\title{
Coupled influence of precipitation regimes and seedling emergence time on the reproductive strategy in Chloris virgata
}

\author{
Ying Wang ${ }^{\text {Corresp., } 1}$, Jiawei Chen ${ }^{1}$, Yige Huang ${ }^{2}$, Zhongsheng Mu ${ }^{3}$, Changfu Wang ${ }^{\text {Corresp. } 1}$ \\ 1 Jilin Jianzhu University, Key Laboratory of Songliao Aquatic Environment, Ministry of Education, Changchun, Jilin, China \\ 2 Environmental Geology, The Fifth Geological Survey Institute of Jilin Province, Changchun, Jilin, China \\ 3 Jilin Academy of Agricultural Sciences, Changchun, Jilin, China \\ Corresponding Authors: Ying Wang, Changfu Wang \\ Email address: wangying19879@aliyun.com, wangcf1973@163.com
}

Precipitation regime and seedling emergence time both influence plant growth and reproduction. However, little attention has been given to the effects of these combined factors on the reproductive strategy of Chloris virgata, which is a vital species in Songnen grassland. Here, we simulated the changes in the precipitation regime and seedling emergence time to evaluate tiller traits and seed production. The results showed that tiller number behaved similarly among three precipitation regimes when sowed on 15 May $\left(T_{1}\right)$, while it increased significantly with precipitation regimes when sowed on 15 June $\left(T_{2}\right)$ and 15 July $\left(T_{3}\right)$. Tiller number decreased significantly with the seedling emergence time under the same water supply treatment. The proportional allocation of reproductive tiller number to total tiller number was significantly higher at $T_{3}$ than at $T_{1}$ and $T_{2}$. Seed number remained similar under different precipitation regimes at $T_{2}$ and $T_{3}$, whereas it was significantly lower under low precipitation than under other water levels at $T_{1}$. Seed number reached the maximum values at $T_{2}$ under the same level of precipitation treatment. Seed size was significantly lower under low precipitation compared to other water supply treatments and the lowest values in seed size, about $0.5 \mathrm{mg}$, occurred at $T_{2}$ under all the precipitation regimes. The lowest values in spike number were under low precipitation at all seedling emergence times. Seed yield exhibited similar trends with seed size under different precipitation regimes, while the greatest gains in these values were at $\mathrm{T}_{1}$ under all the precipitation regimes. Our findings showed that simulated precipitation regimes and seedling emergence time affected the reproductive strategy of $C$. virgata. Typical and high precipitation, as well as early seedling emergence, will improve the seed yield and seed quality in this species. 


\section{Coupled influence of precipitation regimes and seedling emergence}

\section{2 time on the reproductive strategy in Chloris virgata}

3

4

5

6

7

8 Corresponding author: Ying Wang, Changfu Wang

9 E-mail: wangying19879@aliyun.com

10

Jilin Academy of Agricultural Sciences, 130030)

wangcf1973@163.com

Province, China

Telephone and fax number: +860431-84566408

Ying Wang: wangying19879@aliyun.com

Jiawei Chen: 790494611@qq.com

Yige Huang:740488211@qq.com

Zhongsheng Mu:muzs@163.com

Changfu Wang: wangcf1973@163.com

(1. Key Laboratory of Songliao Aquatic Environment, Ministry of Education, Jilin Jianzhu University, Changchun 130118,

People's Republic of China; 2. The Fifth Geological Survey Institute of Jilin Province, Environmental Geology, 130061 , China; 3.

F-Full postal address: 5088 Xincheng Street, Jingyue Economic Development District, Changchun City, Jilin 


\section{Abstract}

26 Precipitation regime and seedling emergence time both influence plant growth and reproduction. However,

27 little attention has been given to the effects of these combined factors on the reproductive strategy of Chloris

28 virgata, which is a vital species in Songnen grassland. Here, we simulated the changes in the precipitation

29 regime and seedling emergence time to evaluate tiller traits and seed production. The results showed that tiller

30 number behaved similarly among three precipitation regimes when sowed on 15 May $\left(T_{1}\right)$, while it increased

31 significantly with precipitation regimes when sowed on 15 June $\left(\mathrm{T}_{2}\right)$ and 15 July $\left(\mathrm{T}_{3}\right)$. Tiller number decreased

32 significantly with the seedling emergence time under the same water supply treatment. The proportional

33 allocation of reproductive tiller number to total tiller number was significantly higher at $T_{3}$ than at $T_{1}$ and $T_{2}$.

34 Seed number remained similar under different precipitation regimes at $T_{2}$ and $T_{3}$, whereas it was significantly

35 lower under low precipitation than under other water levels at $T_{1}$. Seed number reached the maximum values at

$36 \mathrm{~T}_{2}$ under the same level of precipitation treatment. Seed size was significantly lower under low precipitation

37 compared to other water supply treatments and the lowest values in seed size, about $0.5 \mathrm{mg}$, occurred at $\mathrm{T}_{2}$

38 under all the precipitation regimes. The lowest values in spike number were under low precipitation at all

39 seedling emergence times. Seed yield exhibited similar trends with seed size under different precipitation

40 regimes, while the greatest gains in these values were at $T_{1}$ under all the precipitation regimes. Our findings

41 showed that simulated precipitation regimes and seedling emergence time affected the reproductive strategy of

42 C. virgata. Typical and high precipitation, as well as early seedling emergence, will improve the seed yield and

43 seed quality in this species.

44 Key words: reproduction; seed size; seed yield; tiller trait 
45

46

47

\section{Introduction}

Reproduction is one of the most important stages in a plant's life history and is the result of natural selection.

Plants exhibit different reproductive strategies in response to varied environments (Suonan et al., 2017).

Therefore, reproductive strategy plays a major role in plant adaptation by maximizing the overall fitness of plants growing with variable resources (Bazzaz et al., 1987).

Seed yield, one of the vital components in plant restoration, can be determined by inflorescence number, seed number per inflorescence and seed size (Hebblethwaite et al., 1980; Wang et al., 2010). Therefore, environmental conditions experienced by individual plants that affect seed yield will ultimately influence vegetation restoration. Another vital factor for determining seedling establishment and regeneration is seed biology, which is thought to be an important contributor in understanding plant ecological processes within communities (Venable \& Brown, 1988). Seed biology is mainly affected by seed genotype and parental environment (He et al., 2014). Maternal nutrition has been demonstrated as a vital factor that impacts the competitive ability of offspring (Galloway, 2001). Selection pressure for increased seed size may also arise because larger seeds are better at surviving hazards of seedling establishment such as nutrient shortages (Metcalfe \& Grubb, 1997), water availability (Bidgoly et al., 2018; Müller et al., 2019) and temperature (Dewan et al., 2018). Consequently, studies of the reproductive strategies of plants are useful in understanding the adaptation of plants to their natural environment.

Degradation has been severe in the Songnen grassland of China including bare patches that have appeared in this region due to soil salinity and alkalinity. Chloris virgata $\mathrm{Sw}$. is an annual tuft grass with substantial drought and alkali tolerance. Moreover, it is the first species to form a relatively stable and productive singlespecies dominant community (Zheng \& Li, 1999) and is therefore a vital species to restore degraded semi-arid 
66

67

68

69

70

71

72

73

74

75

76

77

78

79

80

81

82

83

84

85

86

grassland.

Precipitation is one of the major factors that limits seed productivity in arid and semiarid areas. Inevitably, the precipitation regime may profoundly influence reproductive traits in perennial and annual grasses (Wang et al., 2010; Wang et al., 2018). Moreover, soil water content has been used to successfully predict seedling emergence (Ikeda et al., 2019). Spring precipitation effects on the vegetation spring phenology in arid and semi-arid regions (Shen et al., 2015). Consequently, there can be major impacts on seedling emergence time due to early or late spring precipitation in wet or dry years, with seedling emergence time influencing the plant's fitness within its community (Du \& Huang, 2008).

Therefore, the objective of this study was to investigate the reproductive traits of this important species in response to combined effects of precipitation regime and seedling emergence time. The findings on the reproductive ecology of this species will inform rational regulatory and management policy for grassland restoration.

\section{Methods and materials}

\section{Experimental design and treatment}

The experiment was conducted at Jilin Jianzhu University, Jilin Province, China in 2016. C. virgata seeds were obtained from the Greenhouse of Jilin Jianzhu University, Jilin Province, China (44³3N, 123 82 31E) in 2015.

Twenty seven PVC pipes, $25 \mathrm{~cm}$ diameter and $50 \mathrm{~cm}$ height, were filled with saline-sodic soils at different sowing dates in 2016. The soil was collected from the surface layer $(0-20 \mathrm{~cm})$ of a grassland near the Northeast Normal University field experiment station, in Changling, Jilin Province, China $\left(123^{\circ} 440\right.$ E, $44^{\circ} 44$

$0 \mathrm{~N}, 167 \mathrm{~m}$ above sea level). The soil total nitrogen was $6.9 \%$, organic carbon $0.4 \%, \mathrm{pH} 8.6$, electrical conductivity $91 \mu \mathrm{sm}^{-1}$ and field capacity of $200 \mathrm{~g} \mathrm{~kg}^{-1}$. And the maximum/minimum temperatures were 32/16 
87

${ }^{\circ} \mathrm{C}$ (day/night) during the treatment period from 15 June to 15 September. The soil-filled pipes were all buried in the soil and the top edge of each pipe and the soil surface were kept at the same level. Twenty seeds were sown on 15 May $\left(T_{1}\right), 15$ June $\left(T_{2}\right)$ and 15 July $\left(T_{3}\right)$, respectively, to ensure three seedling emergence times (SETs). Most seedlings emerged $5 \mathrm{~d}$ after sowing and 10 uniform and robust seedlings were selected per pipe $10 \mathrm{~d}$ after sowing. Three treatments were used to simulate local precipitation regimes (PRs), corresponding to 120 (L: low, soil moisture was 6.0\%), 200 (T: typical, soil moisture was 11.0\%), and 280 (H: high, soil moisture was $19.0 \%$ ) mm precipitation, and these were created by adding water every $5 \mathrm{~d}$ to the pipes from 30 $\mathrm{d}$ after seedling emergence (see Wang et al., 2018). The typical precipitation regime was based on the average amount and frequency of the local region's precipitation (June-October) over the past 21 years in the Songnen grassland, where $C$. virgata is widely distributed. The low and high precipitation regimes were $40 \%$ lower and higher than the typical precipitation regime, based on data from the Songnen grassland in wet and dry years, respectively. For example, the plants were watered $12.5 \mathrm{~mm} 5 \mathrm{~d}$ intervals (The number of precipitation was 16 from 15 June to 15 September because most precipitations occurred in this period) under typical precipitation regime. Then the precipitation was calculated according to the precipitation depth and cross section of the pipe.

There were 3 replicates for each precipitation level at each seedling emergence time, giving 30 individuals per treatment for determining tiller traits and seed production. There was a total of 27 pipes across all treatments for the three seedling emergence times and the pipes were arranged outdoors in a replicated randomized block design under a rain shelter made from transparent $0.2 \mathrm{~mm}$ polyethylene sheeting on $15^{\text {th }}$ May, 2016 .

\section{Data collection}

The plants from each treatment at each seedling emergence time were harvested in mid-September, when all $C$.

virgata individuals were fully mature. Some pipes were damaged by locusts during the course of the 
108

109

110

111

112

113

114

115

116

117

118

119

120

121

122

123

124

125

126

127

128

experiment and were excluded from the analyses, giving 22-30 individuals. The numbers of reproductive and vegetative tillers of $C$. virgata were recorded for each individual in each pipe. One first-order tiller was selected randomly from each individual in each pipe. Then the numbers of mature seeds and unripe seeds were counted to obtain seed number. The number of left spikes from each plant were recorded and the spikes were kept in individual paper bags. Fifty seeds were selected randomly from each plant and dried at $65{ }^{\circ} \mathrm{C}$ for $48 \mathrm{~h}$ and weighed to determine mean seed size. The remaining seeds from each plant were dried at $65{ }^{\circ} \mathrm{C}$ for $48 \mathrm{~h}$ and weighed to obtain seed yield.

\section{Data analysis}

All data were tested for the normality and homogeneity and subjected to analyze by SPSS statistical software (version 17.0, SPSS Inc, Chicago, IL). One-way ANOVA was used to analyze variables such as tiller number, proportion of reproductive tiller number to total tiller number, seed number, spike number, seed size and seed yield. Two-way ANOVA was also used to analyze all data under different precipitation regimes over seedling emergence times. Differences under different precipitation regimes and seedling emergence times were analyzed using the least significant difference (1.s.d.) test.

\section{Results}

\section{Vegetative and reproductive tiller growth}

The ANOVA results showed that seedling emergence time individually had a significant effect on vegetative tiller number, and that precipitation regime and seedling emergence time individually had significant effects on reproductive tiller number. However, their interactions had no effect on vegetative tiller number or reproductive tiller number (Table 1). 
129

130

131

132

133

134

135

136

137

138

139

140

141

142

143

144

145

146

147

148

149

Growth and reproduction in the C. virgata plants responded differently to different levels of precipitation

and seedling emergence times (Fig. 1). The vegetative tiller number was similar under different precipitation regimes at $T_{1}$ and $T_{2}$, while significant variations were found among the three precipitation regimes at $T_{3}$ (Fig.

1A). The vegetative tiller number varied significantly within increasing precipitation and the vegetative tiller number was significantly higher under high precipitation than under low precipitation at $T_{3}$. There was no significant change in reproductive tiller number with increasing precipitation at $T_{1}$ (Fig. 1B). At $T_{2}$ the reproductive tiller number was similar between low and typical precipitation but was significantly higher under high precipitation. At $T_{3}$ the reproductive tiller number was similar under typical and high precipitation treatments and was significantly higher than under low precipitation. Vegetative tiller number decreased significantly from $T_{1}$ to $T_{3}$ under all the precipitation regimes. The highest reproductive tiller numbers occurred at $T_{1}$ under the low precipitation regime. The reproductive tiller numbers were significantly higher at $T_{1}$ than at $T_{2}$ under typical precipitation. Furthermore, changes in seedling emergence time did not affect reproductive tiller number under the high precipitation regime (Fig. 1). The proportion of reproductive tiller number to total tiller number were similar between $T_{1}$ and $T_{2}$, while were significantly lower than that at $T_{3}$ (Fig. 2).

\section{Seed production}

The ANOVA results showed that precipitation regime and seedling emergence time individually had significant effects on seed number, seed size, spike number and seed yield (Table 1). Their interactions had an effect on seed size and seed yield. However, their interactions had no effect on seed number and spike number (Table 1).

The seed number and seed size of the $C$. virgata plants were significantly different under the various 
150

151

152

153

154

155

156

157

158

159

160

161

162

163

164

165

166

167

168

169

170

precipitation regimes and seedling emergence times (Fig. 3). Seed number remained unchanged among the three precipitation regimes at $T_{2}$ and $T_{3}$, whereas seed number was significantly lower under low precipitation than under the typical and high precipitation regimes at $\mathrm{T}_{1}$. Within the same precipitation treatment seed numbers were similar at $T_{1}$ and $T_{2}$ and were significantly higher than at $T_{3}$ (Fig. 3A). Seed size was unchanged from $T_{1}$ to $T_{3}$ under typical and high precipitation and was higher than under low precipitation at all sowing times. Within the same precipitation treatment seed size remained unchanged at $T_{1}$ and $T_{3}$ and was higher than at $\mathrm{T}_{2}$ (Fig. 3B).

There was a significant difference in spike number among different levels of precipitation at different seedling emergence times (Table 2). Spike number increased from the low to typical precipitation regimes but under high precipitation there was no further significant change at $T_{1}$. There was a significant difference between low and high precipitation at $\mathrm{T}_{2}$. Spike numbers increased significantly from low to high precipitation at $T_{3}$. Spike numbers remained unchanged from $T_{1}$ to $T_{3}$ under low and high precipitation. While the spike numbers under the typical precipitation regime decreased substantially from $T_{1}$ to $T_{2}$. There was no significant difference between $T_{1}$ and $T_{3}$, or $T_{2}$ and $T_{3}$ under typical precipitation.

Seed yield was significantly higher under the typical precipitation regime than under low precipitation at $T_{1}$ and $T_{3}$, but there was no difference between typical and high precipitation for these two emergence times (Fig. 4). At $T_{2}$ there was no significant difference in seed yield between low and typical precipitation but there was a marked increase under high precipitation. The highest yield values occurred at $\mathrm{T}_{1}$ under all precipitation regimes.

Discussion 
171

172

173

174

175

176

177

178

179

180

181

182

183

184

185

186

187

188

189

190

191

\section{Vegetative and reproductive tiller growth}

Plants select different reproductive strategies according to their growing environment, and the reproductive strategy selected in a given environment should maximize fitness (Zhang et al., 2018). However, resources are the primary factor determining how plants establish their reproductive machinery (Weiner et al., 2009). Reproductive tiller number is an important characteristic influencing seed yield in many plants (Peng et al., 2018). Whether a bud develops into a reproductive or a vegetative tiller is based on the environment and the evolutionary history of the population (Warringa \& Kreuzer, 1996). Our results showed that the trends in tiller number in C. virgata under different precipitation regimes were similar at $\mathrm{T}_{1}$ and $\mathrm{T}_{2}$ but were different at $\mathrm{T}_{3}$.

The trends were similar with the results in 2018 when sowed at the early date. It can be concluded that water might be one of the limiting resource for tiller number at $T_{3}$. Furthermore, the proportional allocation of reproductive tiller number to total tiller number was significantly higher at $T_{3}$ than at $T_{1}$ and $T_{2}$ (Fig. 2). High temperature improved the proportion of reproductive tiller number to total tiller number and the results were consistent with those from previous study (Escalada \& Plucknett, 1975). Plant morphology was affected by temperature and daylength, while many plants did not react to critical periods of photoperiod unless their thermal requirements were met. C. virgata produced tiller 10 days later after sowing. The temperature was higher when C. virgata produced tillers at $\mathrm{T}_{3}$ than that at $\mathrm{T}_{1}$ and $\mathrm{T}_{2}$. Delayed sowing and low precipitation reduced C. virgata growth (total tiller number), while maximized it's reproduction and restoration potential.

This strategy has also evolved in monocarpic species and according to optimal allocation theory, such plants should allocate more resources to reproductive parts to improve seed production in unfavorable environments (Ellner, 1987). 
192

193

194

195

196

197

198

199

200

201

202

203

204

205

206

207

208

209

210

211

212

\section{Seed production}

Seed production are related to plant adaptations to their growing environment. For example, the maternal nutrient environment affects seed size, seed yield and the competitive ability of progeny (Gómez, 2004). In our study, seed size was smaller at $T_{2}$ compared to the other two emergence times. The larger seed size at $T_{1}$ and $\mathrm{T}_{3}$ may indicate higher seed quality because large seed size has been associated with higher seed germination ability and seedling survival as reported by other authors (Cowell \& Doyle, 1993) and in our earlier work (Wang et al., 2018). This also suggests a management method to produce high quality seeds from C. virgata.

Moreover, our results showed that when C. virgata was delayed in emergence beyond $30 \mathrm{~d}$ or $60 \mathrm{~d}$ it produced fewer seeds. It has been demonstrated that sowing date was one of the critical factors for productivity of winter wheat (Triticum aestivum L.) due to different amounts of soil water storage at different sowing times (Ren et al., 2019). Further, Awan and Chauhan (2016) have reported that a delay in emergence would result in fewer seeds returning to the seed bank, which has important implications for vegetation succession and restoration (Shang et al., 2016). However, seed yields were similar among the three water supply treatments and the first-order spike number was one of the most important factors in determining seed yield in our former work (Wang et al., 2018). Seed yields in the current work were higher in typical and high precipitation than under low precipitation. The pattern of seed yield was not consistent with our former work in 2018, and the reason for this might be the different plant densities in the two experiments. However, the first-order spike number (reproductive tiller number) was higher under low precipitation than under typical and high precipitation in these earlier experiments under a density of five plants per pot, whereas the first-order spike number was significantly higher under typical and high precipitation compared to low precipitation with a density of ten plants per pot in the current work (Fig. 1). This indicated the existence of different reproductive 
213 strategies under different plant densities. Here, reproductive tiller number was demonstrated to be an important

214 component for C. virgata seed yield, and future work should explore the effect of plant densities on growth

215 and reproductive characteristics.

\section{Conclusion}

217 In conclusion, simulated precipitation regimes and seedling emergence time affect the reproductive strategy of

218 C. virgata. Increased precipitation did increase seed yield in this study, which suggested that reproduction in $C$.

219 virgata benefits from average and above-average precipitation regimes. In addition, dry years or delayed

220 precipitation during seedling emergence due to climate change might have a negative effect on plant recovery

221 of C. virgata in arid and semiarid areas such as the Songnen grassland. Early sowing in spring might be a

222 strategy to ensure high seed yield and high seed quality by avoiding late-season drought conditions for this

223 species. These results will also provide some important information on management measures for the

224 establishment and recovery of $C$. virgata in degraded grassland.

\section{Acknowledgements}

226 This work was financed by the National Keypoint Research and Invention Program (2019YFD1002603) and

227 National Nature Science Foundation of China (58678273).

\section{Conflict of interest statement}

229 None of the authors of this manuscript have a financial interest related to this work.

\section{References}


232 Awan TH, Chauhan BS. 2016. Effect of emergence time, inter- and intra-specific competition on growth and 233 fecundity of Echinochloa crus-galli in dry-seeded rice. Crop Protection 87: 98-107. doi:10.1016/j.cropro.2016.05.004.

Bazzaz FA, Chiarello NR, Coley PD, Pitelka LF. 1987. Allocating resources to reproduction and defense. Bioscience 37: 58-67. doi:10.2307/1310178.

237

238

239

240

241

242

Bidgoly RO, Balouchi H, Soltanic E, Moradi A. 2018. Effect of temperature and water potential on Carthamus tinctorius L. seed germination: Quantification of the cardinal temperatures and modeling using hydrothermal time. Industrial Crops and Products 113:121-127.

doi:10.1016/j.indcrop.2018.01.017.

Chauhan BS, Abugho SB. 2013. Effects of water regime, nitrogen fertilization, and rice plant density on growth and reproduction of lowland weed Echinochloa crus-galli. Crop Protection 54:142-147. doi:10.1016/j.cropro.2013.08.005.

Cowell LF, Doyle PJ. 1993. Nitrogen use efficiency. In Impact of macronutrients on crop response and environmental sustainability on the Canadian prairies-a review (eds DA Rennieet al.), pp. 49-109. Ottawa, Canada: Canadian Society of Soil Science.

Dewan S, Mijnsbrugge KV, Frenne PD, Steenackers M, Michiels B, Verheyen K. 2018. Maternal temperature during seed maturation affects seed germination and timing of bud set in seedlings of European black poplar. Forest Ecology \& Management 410:126-135. doi:10.1016/j.foreco.2018.01.002.

Du YJ, Huang ZL. 2008. Effects of seed mass and emergence time on seedling performance in Castanopsis chinensis. Forest Ecology and Management 255:2495-2501. doi:10.1016/j.foreco.2008.01.013. 
253 Ellner S. 1987. Alternate plant life-history strategies and coexistence in randomly varying environments.

254

255

256

257

258

259

260

261

262

263

264

265

266

267

268

269

270

271

272

273

Vegetation 69:199-208. doi:10.1007/BF00038701.

Escalada RG, Plucknett DL. 1975. Ratoon cropping of Sorghum: II. Effect of daylength and temperature on tillering and plant development. Agronomy Journal 67(4): 479-484. doi:10.2134/agronj1975.00021962006700040007x.

Galloway LF. 2001. The effect of maternal and paternal environments on seed characters in the herbaceous plant Campanula americana (Campanulaceae). American Journal of Botany $\mathbf{8 8}$ :

832-840. doi:10.2307/2657035.

Gómez JM. 2004. Bigger is not always better: conflicting selective pressures on seed size in Quercus ilex. Evolution 58:71-80. doi:10.1111/j.0014-3820.2004.tb01574.x.

Hebblethwaite PD, Wright D, Noble A. 1980. Some physiological aspects of seed yield in Lolium perenne L. (perennial ryegrass). In: P.D. Hebblethwaite, editor, Seed production: Proceedings of the 28th Easter School in Agricultural Science, Nottingham, UK. September 1978. Butterworths, London. p. 71-90

He HZ, de Souza Vidigal D, Snoek LB, Schnabel S, Nojveen H, Bentsink L. 2014. Interaction between parental environment and genotype affects plant and seed performance in Arabidopsis. Journal of Experimental Botany 65: 6603-6615. doi:10.1093/jxb/eru378.

Ikeda H, Kinoshita T, Yamamoto T, Yamasaki A. 2019. Sowing time and temperature influence bulb development in spring-sown onion (Allium cepa L.). Scientia Horticulturae 244:242-248. doi:10.1016/j.scienta.2018.09.050.

Metcalfe DJ, Grubb PJ. 1997. The responses to shade of seedlings of very small-seeded tree and shrub species from tropical rain forest in Singapore. Functional Ecology 11:215-221. 
doi:10.1046/j.1365-2435. 1997.00070.x.

275

276

277

278

279

280

281

282

283

284

285

286

287

288

289

290

291

292

293

Müller FL, Raitt LM, Cyster LF, Cupido CF, Samuels MI, Chimphango SBM, Boatwright JS. 2019. The effects of temperature, water availability and seed burial depth on seed germination and seedling establishment of Calobota sericea(Fabaceae). South African Journal of Botany 121:224-229. doi:10.1016/j.sajb.2018.11.012.

Peng D, Tan XF, Zhang L, Yuan DY, Lin JZ, Liu XM, Jiang YQ, Zhou B. 2015. Increasing branch and seed yield through heterologous expression of the novel rice S-acyl transferase gene OsPAT15 in Brassica napus L. Breed Science 68:326-335. doi:10.1270/jsbbs. 17126.

Ren AX, Sun M, Wang PR, Xue LZ, Lei MM, Xue JF, Gao ZQ, Yang ZP. 2019. Optimization of sowing date and seeding rate for high winter wheat yield based on pre-winter plant development and soil water usage in the Loess Plateau, China. Journal of Integrative Agriculture 18:33-42. doi:10.1016/S20953119(18)61980-X.

Shen MG, Piao SL, Cong N1, Zhang GX1, Jassens IA. 2015. Precipitation impacts on vegetation spring phenology on the Tibetan Plateau. Global Change Biology 21(10):36-47. doi: 10.1111/gcb.12961.

Shang ZH, Yang SH, Wang YL, Shi JJ, Ding LM, Long RJ. 2016. Soil seed bank and its relation with above-ground vegetation along the degraded gradients of alpine meadow. Ecological Engineering 90:268277. doi:10.1016/j.ecoleng.2016.01.067.

Suonan ZX, Kim SH, Qin LZ, Lee KS. 2017. Reproductive strategy of the intertidal seagrass Zostera japonica under different levels of disturbance and tidal inundation. Estuarine, Coastal and Shelf Science 197:185-193. doi:10.1016/j.ecss.2017.08.031. 
294

295

296

297

298

299

300

301

302

303

304

305

306

307

308

309

310

311

312

Venable DL, Brown JS. 1988. The selective interactions of dispersal, dormancy, and seed size as adaptations for reducing risk in variable environments. American Naturalist 131:360-383. doi:10.1086/284795.

Wang JF, Xie JF, Zhang YT, Gao S, Zhang JT, Mu CS. 2010. Methods to improve seed yield of Leymus chinensis based on nitrogen application and precipitation analysis. Agronomy Journal 102:277-281. doi:10.2134/agronj2009.0254.

Wang Y, Wang CX, Zhang JK, Wang CQ. 2018. The reproductive strategy in Chloris virgata populations in response to precipitation regimes. Royal Society Open Science 5:180607. doi:10.1098/rsos.180607.

Warringa JW, Kreuzer ADH. 1996. The Effect of New Tiller Growth on Carbohydrates, Nitrogen and Seed Yield per Ear in Lolium perenne L. Annals of Botany 78:749-757. doi:10.1006/anbo.1996.0185.

Weiner J, Campbell LG, Pino J, Echarte L. 2009. The allometry of reproduction within plant populations. Journal of Ecology 97:1220-1233. doi:10.1111/j.1365-2745.2009.01559.x.

Zhang N, Lin JX, Yang YH, Li ZL,Wang Y, Cheng LY, Shi YJ, Zhang YT, Wang JF, Mu CS. 2018. The tolerance of growth and clonal propagation of Phragmites australis (common reeds) subjected to lead contamination under elevated $\mathrm{CO}_{2}$ conditions. RSC Advances 5: 55527-55535. doi:10.1039/c5ra09066k.

Zheng HY, Li JD. 1999. Form and dynamic trait of halophyte community. In Saline plants in Songnen Plain and restoration of alkaline-saline grass (eds JHY Zheng, JD Li), pp. 137-138. Beijing, People's Republic of China: Science Press.

Yeh SY, Chen HW, Ng CY, Lin CY, Tseng TH, Li WH, Ku MSB. 2015. Down-Regulation of Cytokinin Oxidase 2 Expression Increases Tiller Number and Improves Rice Yield. Rice 8:36. 
doi:10.1186/s12284-015-0070-5. 
Table $\mathbf{1}$ (on next page)

Table 1

Analysis of variance of vegetative tiller number, reproductive tiller number, seed number, seed size, spike number and seed yield of $C$. virgata. 
2 Table 1:

3 Analysis of variance of vegetative tiller number, reproductive tiller number, seed number, seed size, spike number and

4 seed yield of $C$. virgata.

\begin{tabular}{|c|c|c|c|c|}
\hline Source & Df & Mean Square & $\mathbf{F}$ & Sig. \\
\hline \multicolumn{5}{|c|}{ Vegetative tiller number $\left(\mathrm{n}\right.$ plant ${ }^{-1}$ ) } \\
\hline SET & 2 & 165.964 & 83.377 & $.000^{* * *}$ \\
\hline PR & 2 & 0.078 & 0.039 & .962 \\
\hline $\mathrm{SET} * \mathrm{PR}$ & 4 & 3.402 & 1.709 & .148 \\
\hline \multicolumn{5}{|c|}{ Reproductive tiller number ( $\mathrm{n}$ plant ${ }^{-1}$ ) } \\
\hline SET & 2 & 16.592 & 11.963 & $.000^{* * *}$ \\
\hline PR & 2 & 18.896 & 13.625 & $.001^{* * *}$ \\
\hline $\mathrm{SET} * \mathrm{PR}$ & 4 & 1.741 & 1.255 & .288 \\
\hline \multicolumn{5}{|c|}{ Seed number $\left(\mathrm{n}\right.$ spike $\left.{ }^{-1}\right)$} \\
\hline SET & 2 & 732947.466 & 41.028 & $.000^{* * *}$ \\
\hline PR & 2 & 99431.410 & 5.566 & $.004^{* *}$ \\
\hline $\mathrm{SET} * \mathrm{PR}$ & 4 & 22621.282 & 1.266 & .284 \\
\hline \multicolumn{5}{|c|}{ Seed size (mg) } \\
\hline SET & 2 & 0.313 & 38.160 & $.000^{* * *}$ \\
\hline PR & 2 & 0.134 & 16.318 & $.000^{* * *}$ \\
\hline $\mathrm{SET} * \mathrm{PR}$ & 4 & 0.020 & 2.498 & $.043^{*}$ \\
\hline Spike numb & & & & \\
\hline
\end{tabular}




\begin{tabular}{lcccc}
\hline SET & 2 & 72.017 & 6.715 & $.001^{* * *}$ \\
PR & 2 & 182.704 & 17.036 & $.000^{* * *}$ \\
SET * PR & 4 & 13.148 & 1.226 & .300 \\
Seed yield $\left(\mathrm{g} \mathrm{m}^{-2}\right)$ & & & \\
SET & 2 & 61.511 & 36.073 & $.000^{* * *}$ \\
PR & 2 & 39.863 & 23.378 & $.000^{* * *}$ \\
SET * PR & 4 & 6.003 & 3.52 & $.027^{*}$ \\
\hline
\end{tabular}

5 *Significant at the 0.05 statistical level.

6 **Significant at the 0.01 statistical level.

$7 \quad * * *$ Significant at the 0.001 statistical level.

8

9

10 
Table 2 (on next page)

Table 2

Table 2: Spike number (mean \pm 1 s.e.) of $C$. virgata under different precipitation regimes at different seedling emergence times. 
2 Table 2:

3 Spike number (mean \pm 1 s.e.) of $C$. virgata under different precipitation regimes at different seedling emergence times.

\begin{tabular}{cccc}
\hline & $\mathbf{T}_{\mathbf{1}}$ & $\mathbf{T}_{\mathbf{2}}$ & $\mathbf{T}_{\mathbf{3}}$ \\
\hline $\mathrm{L}$ & $3.5 \pm 0.41^{\mathrm{bA}}$ & $2.5 \pm 0.33^{\mathrm{bA}}$ & $2.6 \pm 0.32^{\mathrm{cA}}$ \\
$\mathrm{T}$ & $6.5 \pm 1.07^{\mathrm{aA}}$ & $3.5 \pm 0.37^{\mathrm{abB}}$ & $4.6 \pm 0.61^{\mathrm{bAB}}$ \\
$\mathrm{H}$ & $6.1 \pm 0.86^{\mathrm{aA}}$ & $4.6 \pm 0.40^{\mathrm{aA}}$ & $6.2 \pm 0.55^{\mathrm{aA}}$ \\
\hline
\end{tabular}

4 Within a column, means followed by the same lower case letter are not significantly different at $P=0.05$.

5 Within a line, means followed by the same capital letter are not significantly different at $P=0.05$.

6

7

8

9 


\section{Figure 1}

Fig.1

Vegetative tiller number $(A)$ and reproductive tiller number (B) (mean \pm 1 s.e.) of $C$. virgata under different precipitation regimes at different seedling emergence times. Letters $a, b$, and c are used for comparisons between different precipitation regimes, while $a^{\prime}, b^{\prime}$ and c' are used for comparisons between different seedling emergence times. Means with the same letter are not significantly different at $P=0.05$. 

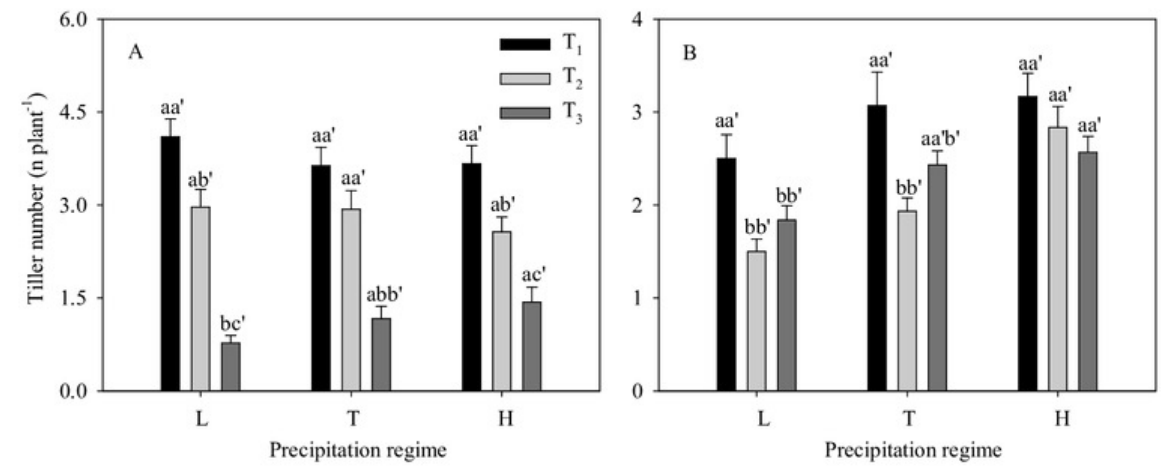


\section{Figure 2}

Fig. 2

Proportion of reproductive tiller number to total tiller number (mean \pm 1 s.e.) of $C$. virgata at different seedling emergence times. Letters $a, b$, and $c$ are used for comparisons between different precipitation regimes. Means with the same letter are not significantly different at $P=0.05$. 


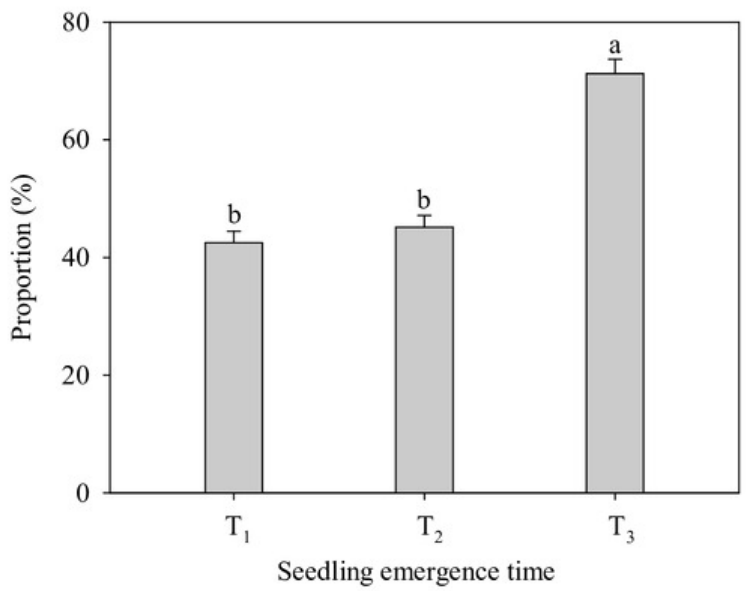




\section{Figure 3}

Fig. 3

Seed number (A) and seed size (B) (mean \pm 1 s.e.) of $C$. virgata under different precipitation regimes at different sowing times. Letters $a, b$, and $c$ are used for comparisons between different precipitation regimes, while $a^{\prime}, b^{\prime}$ and $c^{\prime}$ are used for comparisons between different seedling emergence times. Means with the same letter are not significantly different at $P=0.05$. 

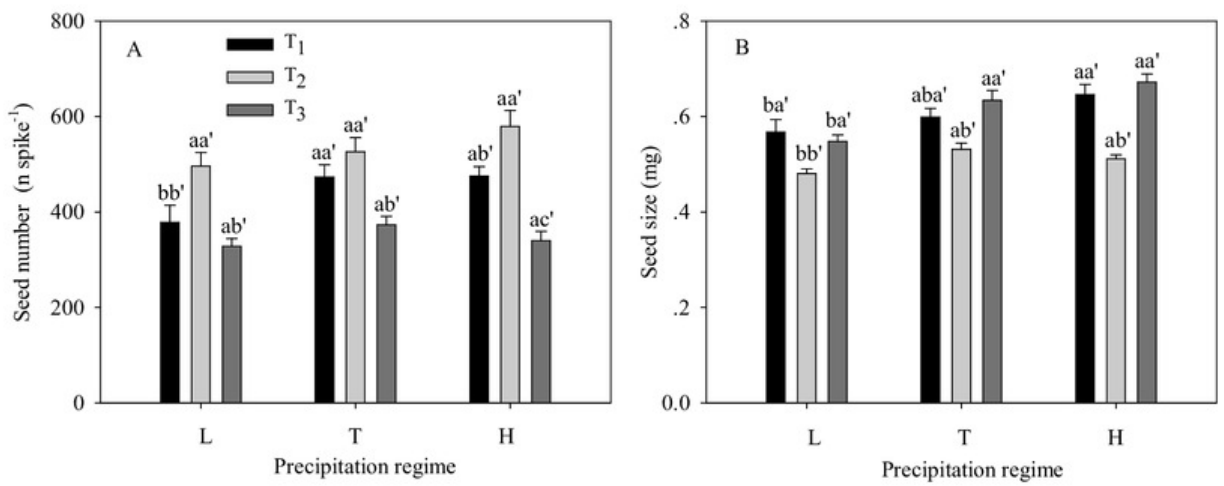


\section{Figure 4}

Fig. 4

Seed yield (mean \pm 1 s.e.) of $C$. virgata under different precipitation regimes at different seedling emergence times. Letters $a, b$, and $c$ are used for comparisons between different precipitation regimes, while $a^{\prime}, b^{\prime}$ and $c^{\prime}$ are used for comparisons between different seedling emergence times. Means with the same letter are not significantly different at $P=0.05$. 


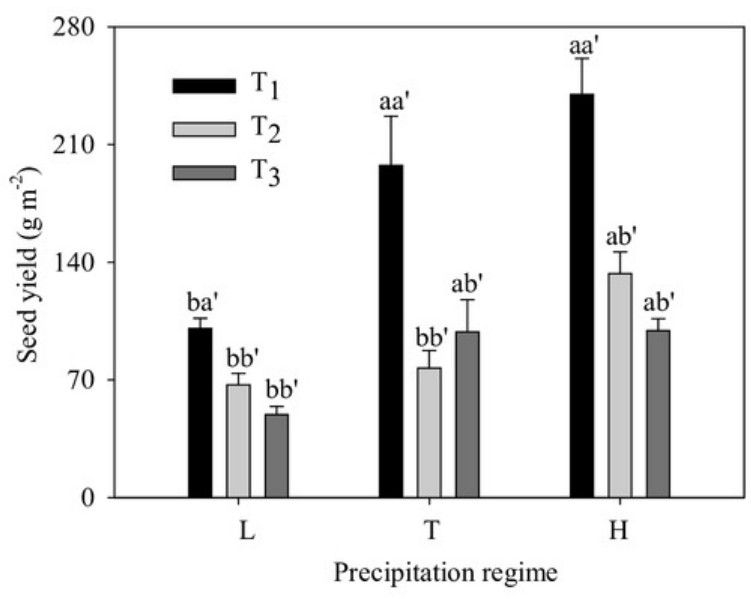

